\title{
Comparison of different angular measurements to assess sagittal Jaw discrepancy in Jaipur population- A cephelometric study
}

\author{
Dr. Rajesh Agarwal ${ }^{1}$, Dr. Lakshya Sharma ${ }^{2}$,Dr. Vikas K. Soni ${ }^{3}$ \\ Dr. Vinod Yadav ${ }^{4}$, Dr. Shami Soni ${ }^{5}$, Dr. Karamdeep Singh ${ }^{6}$ \\ ${ }^{5}$ Professor \&Head,Department of Orthodontics,Jaipur Dental College, Jaipur, India. \\ ${ }^{I}$ Professor, Department of orthodontics, Jaipur Dental College, Jaipur, India. \\ ${ }^{6}$ Assistant professor, Department of orthodontics, Jaipur Dental College, Jaipur, India. \\ ${ }^{2,3,4}$ P. G.Student, Department of orthodontics, Jaipur Dental College, Jaipur, India.
}

\begin{abstract}
:
Introduction: In orthodontic diagnosis and treatment planning an accurate evaluation of sagittal jaw relationship is important. To assess the antero-posterior jaw discrepancy between maxilla and mandible, numerous angular and linear measurements have been in corporate so as to reach correct diagnosis. So the purpose of this study is to compare ANB angle, Wits appraisal, Beta angle and W angle used to measure anteroposterior dysplasia and to find out which is the most reliable amongst them.

Material and method: Sample comprised of 30 pre-treatment lateral Cephalogram which were divided into three groups: Group I-Class I skeletal pattern (n=10), Group II-Class II skeletal pattern $(n=10)$ and Group III - Class III skeletal pattern $(n=10)$

Results: - ANOVA analysis was performed and highly significant differences were found in ANB, Wits Appraisal Beta angle and W-angle in all the three Groups (Group I, Group II, and Group III).

Conclusion: - it has been concluded that similar to the ANB and Wits Appraisal the Beta angle, and W-angle are also significant angles to assess the sagittal jaw relationship between maxilla and mandible.

Key Words-Sagittal Discrepancy, Beta Angle, ANB Angle, Wits Appraisal and W-Angle
\end{abstract}

\section{Introduction}

The evaluation of sagittal jaw relationship between maxilla and mandible has been one of the major problem in the field of orthodontics, which is of prime importance in diagnosis and treatment planning . This is because of rotations of jaws during growth, vertical relationships between the jaws and reference planes, and a lack of validity of the various methods proposed for their evaluation.

Numerous angular and linear measurements have been incorporated to assess the sagittal discrepancy between maxilla and mandible into various cephelometric analyses which could help the clinician to establish the most appropriate treatment plan. Appraisal by

linear measurements has distinct advantages over angular measurements in that there are fewer variables to effect their accuracy and there is less error of measurement.

Downs in 1948 introduced the A-B planeangle. Positive and negative signs wereused to denote protrusion and retrusion ofmandible. A few years later Riedel in 1952 introduced ANB angle and itbecame the most commonly used.

However, both Down's and Riedel's methods are subject to error due to variations in the position of nasion which is not fixed during growth, and any displacement will directly affect the A-B plane angle and ANB angle.

As an alternative to ANB, Jacobson in 1975 introduced Wits appraisal. It relatespoints A and B to the functional occlusalplane. The distance between the points ofintersection $\mathrm{AO}$ and $\mathrm{BO}$ is measured todescribe antero-posterior relationship. Infemales AO should coincide BO, whereas in males BO should be 1 mmahead of AO.Though Wits appraisalavoids point $\mathrm{N}$, accurate identification offunctional occlusal plane is not easy oraccurately reproducible, especially inmixed dentition patients. Secondly, anychange in the angulation of functionalocclusal plane, caused by either tootheruption and dental development ororthodontic intervention, can profoundlyinfluence Wits appraisal.

Baik and Ververidou introduced the beta angle in 2004.Though, it assesses sagittal discrepancies, it depends on points $\mathrm{A}$ and $\mathrm{B}$, which are difficult to locate and point $\mathrm{C}$ in condyle which is not clearly visible either to overcome these problems Bhad 9 et al (2011) developed $\mathbf{W}$-angle. It does not depend on any unstable landmarks or dental occlusion and would be especially valuable to assess true sagittal changes because of growth and orthodontic treatment. So the purpose of this study is to compare the various angles ANB angle, 
Wits appraisal, Beta angle and $\mathrm{W}$-angle used to measure antero-posterior dysplasia and to find out which is the most reliable amongst them.

\section{Material and Methods-}

This study was conducted in the Department of Orthodontics and Dentofacial Orthopedics Jaipur Dental College, Jaipur. It consisted of 30 pre-treatment lateral cephalograms of 15 to 25 year old individuals who had never undergone orthodontic treatment which were divided into 3 groups.

Group I - Class I skeletal pattern group ( $\mathrm{n}=10)$, Group II - Class II skeletal pattern group $(\mathrm{n}=10)$, Group III Class III skeletal pattern group $(\mathrm{n}=10)$ The following inclusion criteria was taken for the Class I skeletal pattern group (1) ANB angle of $1^{\circ}$ to $3^{\circ}$, (2) Wits appraisal between 0 and $-3 \mathrm{~mm}$ (3) Beta angle between $27^{\circ}-35^{\circ}$ degrees, and (4) $\mathrm{W}$-angle between $51^{\circ}-56^{\circ}$ and pleasant profile. The following inclusion criteria was taken for the Class II skeletal pattern group (1) The ANB angle was above $4^{\circ}$ (2) Wits appraisal greater than or equal to -1 $\mathrm{mm}$ (3) Beta angle less than $27^{\circ}$ (4)W-angle less than $51^{\circ}$ and the profile had a Class II appearance. The following inclusion criteria was taken for the Class III skeletal pattern group (1) the ANB angle was less than or equal to $1^{\circ}$ (2) Wits appraisal less than or equal to $-4 \mathrm{~mm}$ (3) Beta angle more than $35^{\circ}$ (4) W angle more than $56^{\circ}$ and the profile had a Class III appearance.

Then the lateral Cephalogram exposed with jaws in centric relation, lips relaxed, and the head in the Natural head position. The radiographs were obtained with Kodak X-ray machine with model no: 8000c (fig 1). All the Cephalogram were recorded with the same exposure parameters and in the same machine. These Cephalogram were traced, and ANB, Wits appraisal, and Beta angle and $\mathrm{W}$-angle were measured to find the antero-posterior dysplasia and most reliable amongst them. (Fig 2).

\section{Statistical Analysis-}
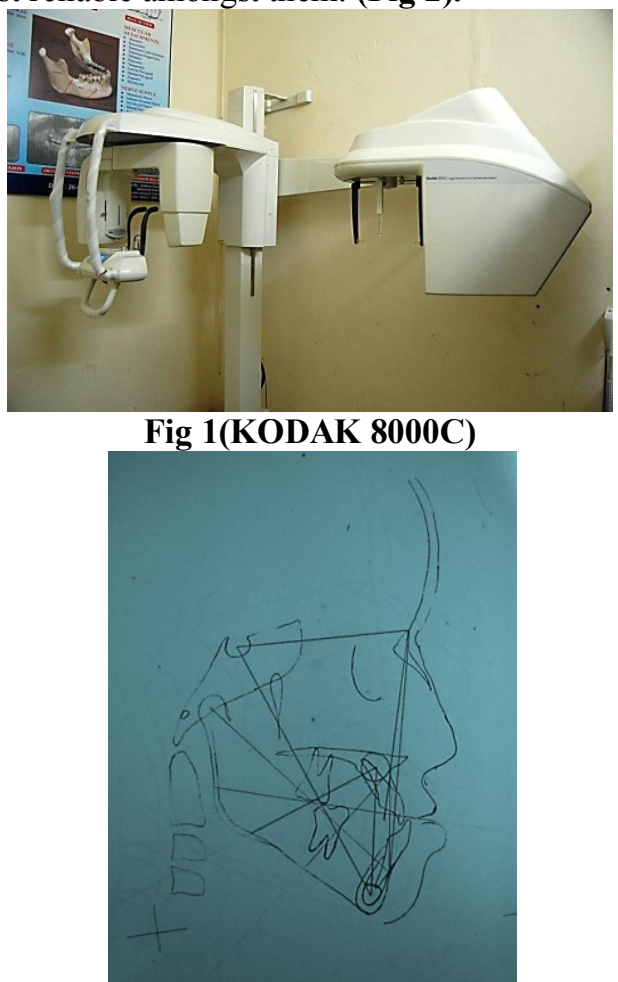

Fig 2(lateral Cephalogram tracing)

The mean, standard deviation and $\mathrm{P}$ value were calculated for each parameter. ANOVA analysis was performed and highly significant differences were found in Beta angle and W-angle in all the three Groups (Group I, Group II, and Group III) (Table I) 
Table I- Mean, Standard Deviation and P-value for the three Groups

\begin{tabular}{|c|c|c|c|c|c|}
\hline & Group & $\mathbf{N}$ & MEAN & STD. DV & P-VALUE \\
\hline \multirow[t]{3}{*}{ ANB } & I & 10 & 1.6 & 0.966092 & $<0.001^{* *}$ \\
\hline & II & 10 & 6.5 & 1.581139 & \\
\hline & III & 10 & 2.6 & 1.349897 & \\
\hline \multirow{3}{*}{$\begin{array}{c}\text { Wits } \\
\text { Appraisal }\end{array}$} & I & 10 & 0.8082 & 0.61202 & 0.723 \\
\hline & II & 10 & 1.0000 & 1.08945 & \\
\hline & III & 10 & 0.6590 & 0.88343 & \\
\hline \multirow[t]{3}{*}{ Beta Angle } & I & 10 & 32.2 & 3.29309 & $<0.001^{* *}$ \\
\hline & II & 10 & 23.8 & 3.735714 & \\
\hline & III & 10 & 39.8 & 2.973961 & \\
\hline \multirow[t]{3}{*}{ W- angle } & I & 10 & 53.4 & 5.25357 & $<0.001^{* * *}$ \\
\hline & II & 10 & 49.6 & 2.412928 & \\
\hline & III & 10 & 59.5 & 1.715938 & \\
\hline
\end{tabular}

**Highly Significant

\section{Discussion-}

Clinicians with increasing frequency are treating malocclusions in conjunction with orthognathic surgery. A method of maxillomandibular assessment that provides accurate data on this relationship at an early age would be highly desirable. ${ }^{5}$ The most popular parameter for assessing the sagittal jaw relationship remains the ANB angle, but it is affected by various factors and can often be misleading. ${ }^{1}$ It has been suggested that although the apical base relationships were constant in all conditions, the ANB angle became either small or large and thus such a measurement was not reliable. So one must consider Bjork opinion that the human body constitutes a functional entity, no part of which can be varied without entailing some changes in other parts. Similarly, the facial skeleton and the dentition are functional parts of the skull as a whole. It follows, therefore, that variations in the bite will be largely related to cranial and facial structures." 12 .

ANOVA analysis was performed and highly significant differences were found in ANB, Wits Appraisal Beta angle and W-angle in all the three Groups (Group I, Group II, and Group III) Showing Highly Significant Value in Between All groups except Wits Appraisal.

The result of this study shows that the ANB angle values are significant $(\mathrm{p}<0.001)$ among three groups but the study conducted by Brown ${ }^{13}$, Chang ${ }^{11}$ and Jacobson ${ }^{1}$, who claimed that any change in the SN plane would affect the ANB angle. This is also supported by Rotberg et $\mathbf{~ a l}^{\mathbf{1 4}}$ who also stated that nasion usually moves in anterior and slightly superior direction because of the growth increments on the cranial base plane passing through sella and nasion. So when using the ANB angle, factors such as the patient's age, growth rotation of the jaws, vertical growth, and the length of the anterior cranial base (AP position of N) should be considered, which makes the interpretation of this angle much more complex (Jacobson, 1975) ${ }^{1}$.

Our study shows that Wits values were non- significant (P- 0.723 ) amongthree groups. This is also supported by Moore et $\mathbf{~ a l ~}^{15}$ and Ishikawa et $\mathrm{al}^{16}$ who also stated that Wits appraisal although not affected by landmarks or jaw rotations; it still has the problem of correctly identifying the functional occlusal plane, which can sometimes be impossible, especially in mixed dentition. Furthermore, changes of the Wits measurement throughout orthodontic treatment might also reflect changes in the functional occlusal plane rather than pure sagittal changes of the jaws.

Our study shows that Beta angle values were statistically significant $(\mathrm{p}<0.001)$ among three groups. This is also supported by Biak and Ververidou ${ }^{3}$ whostated that Beta angle does not depend on cranial landmarks or the functional occlusal plane and remain relatively stable even when the jaws are rotated. Another advantage of the Beta angle is that it can be used in consecutive comparisons throughout orthodontic treatment because it reflects true changes of the sagittal relationship of the jaws, which might be due to growth or orthodontic or orthognathic intervention. But it uses point $\mathrm{A}$ and point $\mathrm{B}$, which can be remodelled by orthodontic treatment and growth.

Our study shows that $\mathrm{W}$ - angle values were statistically significant $(\mathrm{p}<0.001)$ among three groups. This is also supported Bhad et $\mathbf{a l}^{\mathbf{9}}$ who stated that this measurement does not depend on unstable landmarks or the functional occlusal plane. It uses three stable points point $\mathrm{S}$, point $\mathrm{M}$, and point $\mathrm{G}$ and the angle is measured between a perpendicular line from point $\mathrm{M}$ to the SG line and $\mathrm{M}-\mathrm{G}$ line. The geometry of the $\mathrm{W}$ angle also has the advantage to remain relatively stable even when the jaws are rotated or growing vertically this is because of rotation of the S-G line along with jaw rotation, which carries the perpendicular from point $\mathrm{M}$ with it. Therefore, measurement of $\mathrm{W}$ angle is useful sagittal parameter in skeletal patterns with clockwise or counter clockwise rotation of the jaws as well as during transitional period when vertical facial growth is taking place. 


\section{Conclusion-}

It was concluded from the present study that Beta angle and $\mathrm{W}$-angle are statistically significant angles to assess the sagittal jaw relationship between maxilla and mandible and can be used as adjuncts to ANB angle and Wits appraisal,

\section{References-}

[1]. Jacobson A: The "Wits" appraisal of jaw disharmony. Am J Orthod 1975; 67: 125-138.

[2]. Moyers RE, Bookstein FL, Guire KE: The concept of pattern in craniofacialgrowth. Am J Orthod 1979; 76: 136- 148

[3]. Baik CY, Ververidou M: A new approach of assessing sagittal discrepancies: the Beta angle. Am J Orthod Dentofac Orthop 2004;

[4]. 126100-105

[5]. Nanda R 2005: Biomechanics and esthetic strategies in clinical orthodontics. Elsevier, St. Louis. pp. 38-73

[6]. Na n d a R , Me r r i 11 RM : Cephalometric assessment of sagittal relationship between maxilla and mandible: Am J Orthod Dentofac

[7]. Orthop 1994;105:328-44

[8]. Downs WB: Variations in facial relationships: Their significance in treatment and prognosis: Am J Orthod 1948;34:812-823

[9]. Riedel RA: The relation of maxillary structures to cranium in malocclusionand in normal occlusion. Angle Orthod 1952;22:142-145

[10]. Bhad WA, Nayak S and Doshi UH: A new approach of assessing sagittaldysplasia: the W angle : European Journal of Orthodontic

[11]. 2011:1-5

[12]. Freeman RS : Adjusting A-N-B angles to reflect the effect of maxillary position : Angle Orthod1981;51:162-71

[13]. Ch a $\mathrm{n}$ g HP: As s e s sme n t o f anteroposterior jaw relationship: Am J Or th o d De $\mathrm{n}$ t o f a c Or t h o p 1987;92:117-22

[14]. Oktay H: A comparison of ANB, WITS , A F - B F A N D A P D I measurements : Am J Orthod Dentofac Orthop 1991; 99: 122-8

[15]. Brown M: Eight methods of analyzing a cephalograms to establish anteroposterior skeletal di $s$ c $r$ epancy : Br J Or thod 1981:8;139-46

[16]. Rotberg S, Fried N, Kane J, Shapiro E : Predicting the " Wits appraisal from the ANB angle : Am J Orthod 1980:77;636-42

[17]. Moore RN, DuBois LM, Boice PA, Igel KA: The accuracy of measuring condylion location. Am J Orthod Dentofac Orthop 1989; 95:

[18]. 344-347

[19]. Ishikawa H, Nakamura S, Hiroshi I, and Kitazawa S: Seven parameters describing anteroposterior jaw relationships: post pubertal

[20]. prediction accuracy and interchange ability. Am J Orthod Dentofac Orthop 2000;117: 714-720 